3. Медведский В.А., Догель А.С. какой коровник лучше? // Животноводство России. - 2016. - № 4. C. $19-21$.

4. Новиков Н.Н. Моделирование воздушных потоков и расчет элементов аэрационных систем микроклимата животноводческих помещений // Вестник ВНИИМЖ. - 2011. - № 4 (4). - С. 34-42.

5. РД-АПК 1.10.01.03-12 Методические рекомендации по технологическому проектированию ферм крупного рогатого скота крестьянских (фермерских) хозяйств. М.: ФГБНУ «Росинформагротех», 2012. - 167 с.

6. Ходанович Б. «Холодные» коровники: уроки суровой зимы и жаркого лета // Животноводство России. - 2011. - № 2. - С. 37-39.
7. Muller H.J., Moller B. Application of natural ventilation in cattle barns // Proceedings of Clima 2007. Well being indoors. - Режим доступа: http://www.inive.org/ members_area/medias/pdf/Inive\%5Cclima2007\%5CA0 9\%5CA09P1406.pdf.

Абрамкина Дарья Викторовна, канд. техн. наук, доцент кафедры «Теплогазоснабжение и вентиляция», Национальный исследовательский Московский государственный строительный университет. Россия.

129337, г. Москва, Ярославское шоссе, 26.

Тел.: (495) 781-80-07.

Ключевые слова: аэрация; коровник; вентиляиия; воздухообмен; коэффициент расхода.

\title{
AERATION OF THE PREMISES OF THE DAIRY COWS KEEPING IN THE LIGHT WEIGHT DESIGN IN THE WARM PERIOD OF THE YEAR
}

\begin{abstract}
Abramkina Darya Viktorovna, Candidate of Technical Sciences, Associate Professor of the chair "Heat and Gas Supply and Ventilation", National Research Moscow State University of Civil Engineering. Russia.
\end{abstract} rate.

Keywords: aeration; cowshed; ventilation; air exchange; flow
The purpose of the article is to conduct multivariate calculations of aeration in a building at dairy cows keeping in order to identify the most effective way of ensuring normal air exchange in the stall house. According to the results of studies, it was found out that the supply air flow through the external gate makes a significant contribution to the overall air exchange of the stall house.

удк 697.921.2

\section{РАСЧЕТ АЭРАЦИИ СЕЛЬСКОХОЗЯЙСТВЕННОГО ЗДАНИЯ МОЛОЧНОГО ПРОИЗВОДСТВА В ХОЛОДНЫЙ ПЕРИОД ГОДА}

\author{
АГАХАНОВА Каминат Мурадовна, Национальный исследовательский Московский \\ государственный строительный университет
}

Представлены результаты многовариативных расчетов систем аэрации, проведенных для «холодного коровника» на 200 голов в зимний период года при различных температурах наружного воздуха. Определен требуемый угол раскрытия створки аэрационного проема, позволяющий обеспечить нормируемый расход воздуха в помещении содержания крупного рогатого скота.

Введение. В сельскохозяйственных зданиях молочного производства для осуществления вентиляции помещений содержания скота зачастую предусматривают системы аэрации. Основными элементами данных систем являются: вентиляционные проемы, расположенные по всей длине наружных стен и необходимые для обеспечения притока наружного воздуха, а также аэрационные фонари, через которые осуществляются вытяжка и естественное освещение помещения. Особенности конструкции, размеры и месторасположение перечисленных элементов определяют эффективность работы систем вентиляции в течение рассматриваемого периода эксплуатации [5].

Сочетание температуры, относительной влажности и подвижности внутреннего воздуха в помещении влияет на процессы терморегуляции организма животного и, как следствие, на его продуктивность [1]. В холодный период года нормируемая температура внутреннего воздуха в коровниках составляет $10{ }^{\circ} \mathrm{C}$ при температуре наружного воздуха до $-25{ }^{\circ} \mathrm{C}$ и $3{ }^{\circ} \mathrm{C}$ при более низких температурах наружного воздуха, относительная влажность 40-75\% [6]. При понижении температуры ниже рекомендованного значения существует опасность замерзания систем поения и уборки навоза, переохлаждения и болезни коров, особенно находящихся в лежачем положении [4].

Проектирование «холодных коровников», в которых аэрация помещения осуществляется на протяжении всего года, является наиболее сложной инженерной задачей. В зимний период система естественной вентиляции должна не только обеспечивать требуемый воздухообмен в помещении, но и исключить возможность появления сквозняков [7].

Помещения для содержания скота, выполненные из облегченных конструкций, позволяют содержать животных в естественных климатических условиях, что позволяет значительно повысить качество молока [2]. Как показывают результаты исследований [3], температура 
внутреннего воздуха в «холодном коровнике» в течение всего года находится в диапазоне комфортных параметров, за исключением холодных месяцев. В период с ноября по февраль температура внутреннего воздуха превышала допустимые значения, что связано с неправильным регулированием аэрационных проемов.

Методика исследований. Для определения требуемой площади приточных и вытяжных отверстий, а также угла открытия аэрационного проема была проведена серия многовариативных расчетов при различной температуре наружного воздуха. В качестве исходных данных использована температура наиболее холодной пятидневки, а также средние температуры в зимний период (с декабря 2008 по февраль 2019 г. включительно). Зима 2015-2016 гг. в расчетах не учитывалась в связи с отсутствием данных на метеостанции.

Результаты исследований. Расчет аэрации был выполнен для коровника, расположенного в г. Дмитров, на 200 гол. с габаритными размерами $18 \times 57 \times 9(h)$ м. Приточные аэрационные отверстия расположены по всей длине сооружения, выходная вентиляция осуществляется через светоаэрационный конек здания. Расстояние между приточными и вытяжными отверстиями составляет 5 м. Для выполнения расчета аэрации были выполнены предварительные расчеты [3], результаты которых представлены в табл. 1.

Створки аэрационных отверстий имеют различные углы раскрытия, в зависимости от которых меняется площадь приточного отверстия и, соответственно, расход воздуха через них. Для определения площади аэрационных отверстий был выполнен расчет аэрации на совместное действие гравитационного давления и ветра (прямая задача). Расчет выполнялся на расчетные для системы отопления параметры наружного воздуха и минимальный угол раскрытия створки 3 град для возможности увеличить площадь приточного отверстия при меньшей разности давлений с обеих сторон от проема. За расходы приточного и вытяжного воздуха были приняты минимальные объемы приточного и вытяжного воздуха по зоогигиеническим нормативным требованиям.

Расчетное давление аэрации, Па:

$$
\Delta P_{\text {расч }}=\left(K_{\text {аэр.н }}-K_{\text {аэр.3 }}\right) \frac{v_{\mathrm{H}}^{2}}{2} \rho_{\mathrm{H}}+g H\left(\rho_{\mathrm{H}}-\rho_{\text {вн }}\right) \text {, }
$$

где $K_{\text {аэр.н }}$ - аэродинамический коэффициент на фасаде с наветренной стороны, принимается равным 0,$8 ; K_{\text {аэр.з }}$ - аэродинамический коэффициент на фасаде с заветренной стороны, принимается равным 0,$5 ; \rho_{\text {н }}, \rho_{\text {вн }}-$ плотность наружного и внутреннего воздуха, кг $/ \mathrm{m}^{3} ; H$ - расстояние по вертикали между осями приточных и вытяжных отверстий, м.

Характеристика $A$ :

$$
A=\left(\frac{G_{\text {прит }}}{G_{\text {выт }}}\right)^{2} \frac{\rho_{\text {уд }}}{\rho_{\text {н }}} .
$$

где $\rho_{\text {уд }}$ - плотность удаляемого воздуха, кг $/ \mathrm{M}^{3}$.

Величина расчетного давления аэрации, расходуемого в приточных проемах, Па:

$$
\Delta P_{\text {пр }}=\frac{1}{1+A} \Delta P_{\text {расч }} .
$$

Величина расчетного давления аэрации, расходуемого в вытяжных проемах, Па:

$$
\Delta P_{\text {выт }}=\Delta P_{\text {расч }}-\Delta P_{\text {пр }} \text {. }
$$

Требуемые площади приточных и вытяжных отверстий:

$$
\begin{gathered}
A_{\text {пр }}=\frac{G_{\text {пр }}}{3600 \mu_{\text {пр }} \sqrt{2 P_{\text {пр }} \rho_{\text {н }}}} . \\
A_{\text {выт }}=\frac{G_{\text {p }}}{3600 \mu_{\text {выт }} \sqrt{2 P_{\text {выт } \rho_{\text {уд }}}}} .
\end{gathered}
$$

где $\mu_{\text {пр}}, \mu_{\text {выт }}-$ коэффициент расхода.

Коэффициент расхода зависит от угла раскрытия створки окна $\alpha$ и может быть вычислен по формуле

$$
\mu=0,62 \sin \alpha .
$$

В результате расчета были определены площади аэрационных отверстий: $A_{\text {пр }}=30,462 \mathrm{M}^{2}$, $A_{\text {выт }}=30,462 \mathrm{M}^{2}$.

Для исследования работы аэрации в течение холодного периода были выполнены расчеты аэрации на средние за зимнее время года (за декабрь, январь и февраль) температуры при тех же аэрационных отверстиях и углах раскрытия

\begin{tabular}{|c|c|c|c|c|c|c|c|c|}
\hline \multirow{2}{*}{$\begin{array}{c}\text { Район } \\
\text { строи- } \\
\text { тельства }\end{array}$} & \multirow{2}{*}{$\begin{array}{c}\text { Температу- } \\
\text { ра наружно- } \\
\text { го воздуха в } \\
\text { ХП } t_{\mathrm{H}},{ }^{\circ} \mathrm{C}\end{array}$} & \multirow{2}{*}{$\begin{array}{c}\text { Ско- } \\
\text { рость } \\
\text { ветра в } \\
\text { ХП }{ }_{\text {н, }} \\
\text { м/с }\end{array}$} & \multirow{2}{*}{$\begin{array}{c}\text { Явные } \\
\text { теплопос- } \\
\text { тупления } \\
Q_{\sharp}, \text { кВт }\end{array}$} & \multirow{2}{*}{$\begin{array}{c}\text { Минималь- } \\
\text { ный объем } \\
\text { воздуха } \\
L_{\text {прит }} L_{\text {выт' }}, \\
\text { Кг/ч }\end{array}$} & \multicolumn{2}{|c|}{$\begin{array}{l}\text { Температура внут- } \\
\text { реннего воздуха } t_{\text {вн }} \text {, } \\
{ }^{\circ} \mathrm{C}\end{array}$} & \multicolumn{2}{|c|}{$\begin{array}{l}\text { Температура удаляе- } \\
\text { мого воздуха } t_{\text {уд }},{ }^{\circ} \mathrm{C}\end{array}$} \\
\hline & & & & & $\begin{array}{c}\text { при } \\
t>-25^{\circ} \mathrm{C}\end{array}$ & $\begin{array}{c}\text { при } \\
t>-25^{\circ} \mathrm{C}\end{array}$ & $\begin{array}{c}\text { при } \\
t>-25^{\circ} \mathrm{C}\end{array}$ & $\begin{array}{c}\text { при } \\
t>-25^{\circ} \mathrm{C}\end{array}$ \\
\hline Дмитров & -28 & 3,8 & 117,4 & 18000 & 10 & 3 & 12,25 & 5,25 \\
\hline
\end{tabular}
их створок (табл. 2). Температура внутреннего воздуха принималась равной $10^{\circ} \mathrm{C}$, т.к. наружная для г. Дмитров ниже $-25^{\circ} \mathrm{C}$.

Исходные данные и результаты предварительного расчета явных тепловых поступлений в коровник 
Результаты расчета аэрации в холодный период года

\begin{tabular}{|c|c|c|c|c|c|}
\hline Период & $\begin{array}{c}t,{ }^{\circ} \text { С (средняя за } \\
\text { декабрь, январь } \\
\text { и февраль) }\end{array}$ & $\begin{array}{c}\text { Коэффициент рас- } \\
\text { хода (угол раскры- } \\
\text { тия створки, град) }\end{array}$ & $\begin{array}{c}\text { Расход } \\
\text { воздуха, кг/ч }\end{array}$ & $\begin{array}{c}\text { Коэффициент } \\
\text { расхода (угол } \\
\text { раскрытия створки) }\end{array}$ & $\begin{array}{c}\text { Расход } \\
\text { воздуха, кг/ч }\end{array}$ \\
\hline $2008-2009$ & $-4,9$ & $0,032(3)$ & 15510 & $0,038\left(3,5^{0}\right)$ & 18420 \\
\hline $2009-2010$ & $-10,8$ & $0,032(3)$ & 16410 & $0,036\left(3,4^{0}\right)$ & 18470 \\
\hline $2010-2011$ & $-9,9$ & $0,032(3)$ & 16280 & $0,036\left(3,3^{0}\right)$ & 18310 \\
\hline $2011-2012$ & $-6,8$ & $0,032(3)$ & 15800 & $0,037\left(3,4^{0}\right)$ & 18270 \\
\hline $2012-2013$ & -8 & $0,032(3)$ & 15980 & $0,037\left(3,4^{0}\right)$ & 18480 \\
\hline $2013-2014$ & $-5,1$ & $0,032(3)$ & 15540 & $0,038\left(3,5^{0}\right)$ & 18310 \\
\hline $2014-2015$ & $-4,3$ & $0,032(3)$ & 15420 & $0,038\left(3,5^{0}\right)$ & 18260 \\
\hline $2015-2016$ & Нет данных & Нет данных & Нет данных & Нет данных & Нет данных \\
\hline $2016-2017$ & $-6,7$ & $0,032(3)$ & 15790 & $0,037\left(3,4^{0}\right)$ & 18250 \\
\hline $2017-2018$ & $-5,2$ & $0,032(3)$ & 15560 & $0,038\left(3,5^{0}\right)$ & 18470 \\
\hline $2018-2019$ & $-5,5$ & $0,032(3)$ & 15600 & $0,037\left(3,4^{0}\right)$ & 18040 \\
\hline
\end{tabular}

При более высоких температурах наружного воздуха площади приточных и вытяжных проемов при углах раскрытия створок 3 град недостаточно для обеспечения минимально необходимого объема приточного и вытяжного воздуха. Есть необходимость регулирования степени открытости створки в течение сезона. В результате многовариантных расчетов были определены минимальные углы, при которых обеспечивается требуемый воздухообмен в коровнике (см. табл. 1) в рассматриваемый период года.

Заключение. Как показали результаты расчетов, коэффициент расхода воздуха и, следовательно, угол раскрытия створки окна меняются незначительно. Для удобства эксплуатации «холодного коровника» в течение зимнего периода времени рекомендуется применять аэрационные проемы с коэффициентом расхода, равным 0,038, что позволит обеспечить нормируемый расход воздуха в помещении согласно зоогигиеническим нормативным документам.

При понижении температуры наружного воздуха до $-28^{\circ} \mathrm{C}$, расход приточного воздуха составит 22310 кг/ч.

\section{СПИСОК ЛИТЕРАТУРЫ}

1. Догель А.С., Медведский В.А. Влияние условий содержания на продуктивность коров и качество получаемого молока / / Актуальные проблемы интенсивного развития животноводства. - 2016. - №19 (2) . - С. 222-227.
2. Медведский В.А., Догель А.С. Влияние условий содержания на продуктивность коров и качество получаемого молока // Актуальные проблемы интенсивного развития животноводства. - 2016. - № 19. C. 222-227.

3. Медведский В.А., Догель А.С. Коровник облегченного типа. Где комфорт, там и продуктивность // Тваринництво України. - 2016. - № 3. - С. 4-7.

4. Микроклимат коровника на 200 голов в зимний период / В.Ф. Вторый [и др.] // Вестник ВНИИМЖ. 2017. - № 4 (28). - С. 99-103.

5. Новиков Н.Н. Моделирование воздушных потоков и расчет элементов аэрационных систем микроклимата животноводческих помещений // Вестник ВНИИМЖ. - 2011. - № 4 (4). - С. 34-42.

6. РД-АПК 1.10.01.03-12 Методические рекомендации по технологическому проектированию ферм крупного рогатого скота крестьянских (фермерских) хозяйств. - М.: ФГБНУ «Росинформагротех», 2012. $167 \mathrm{c}$.

7. Ходанович Б. «Холодные» коровники: уроки суровой зимы и жаркого лета // Животноводство России. - 2011. - № 2. - С. 37-39.

Агаханова Каминат Мурадовна, преподаватель кафедры «Теплогазоснабжение и вентиляция», Национальный исследовательский Московский государственный строительный университет. Россия.

129337, г. Москва, Ярославское шоссе, 26.

Тел.: (495) 781-80-07.

Ключевые слова: аэрация; холодный коровник; вентиляция; воздухообмен; коэффициент расхода.

\section{CALCULATION OF AERATION OF AN AGRICULTURAL BUILDING OF DAIRY PRODUCTION IN THE COLD SEASON}

Agakhanova Kaminat Muradovna, Teacher of the chair "Heat and Gas Supply and Ventilation", National Research Moscow State University of Civil Engineering. Russia.

Keywords: aeration; cold cowshed; ventilation; air exchange; flow rate.
They are given results of multivariate calculations of aeration systems carried out for a "cold cowshed" for 200 animals in the winter season at various outdoor temperatures. The required opening angle of the flap of the aeration opening is determined, which allows ensuring a normalized air flow during the cattle housing. 